\title{
Quality of Life and Disability in Stroke Survivors
}

\section{*Dayana Shakya ${ }^{1}$, Rosy Chaudhary $^{2}$, Dipesh Shakya ${ }^{3}$, Bikram Shakya ${ }^{4}$}

${ }^{1}$ Lecturer, B. Sc. Nursing Program, Kathmandu Medical College, Bhaktapur, Nepal

${ }^{2}$ Master of Public Health (Advanced), Torrens University, Wakefield Street, Adelaide, Australia

${ }^{3}$ Lecturer, Department of Neuromedicine, Kathmandu Medical College, Kathmandu, Nepal

${ }^{4}$ Lecturer, Department of Neurosurgery, Kathmandu Medical College, Kathmandu, Nepal

\section{*Corresponding Author:}

\section{Dayana Shakya}

Contact: dianashakya@gmail.com,+977-9849511461

\begin{abstract}
Introduction: With advancing the treatment of stroke patients, their mortality has decreased but morbidity and disability have increased. Hence, it becomes increasingly important to find measures to improve these areas. The study aims to assess the quality of life (QOL) and disability in stroke survivors at least six months post-stroke.
\end{abstract}

Methods: Descriptive, cross-sectional design was used to assess the QOL and disability in stroke patients attending Neuromedicine and Neurosurgery out-patient departments of Kathmandu Medical College. Data was collected purposively using an interview from 155 respondents. QoL was assessed using Health-Related Quality of Life in Stroke Patients (HRQOLISP-40) and disability was measured by using the World Health Organization Disability Assessment Schedule 2.0 (WHODAS 2.0). The analysis was done using Pearson's correlation and the Mann Whitney U test.

Results: The QOL was found to be the best in the 'ecosocial' and worst in the 'soul' domain. In disability, patients scored the best in 'Getting along with people' and 'self-care' domains and worst in the 'life activities: school/ work' domain. Respondents with hemorrhagic stroke, only one admission and those who did not exercise had better QOL. Patients with less than 10 years of formal education, those not earning and those with comorbidities had more disability. Correlation analysis showed better QOL with lesser age, higher monthly family income, and higher Barthel index whereas higher disability was found in respondents with higher age and lower Barthel index.

Conclusion: Disability in stroke patients needs to be addressed in order to improve their QOL. The domains affected should be given attention during the rehabilitation of stroke patients.

Keywords: Cerebrovascular accident, Disability, Nepal, Quality of life, Stroke

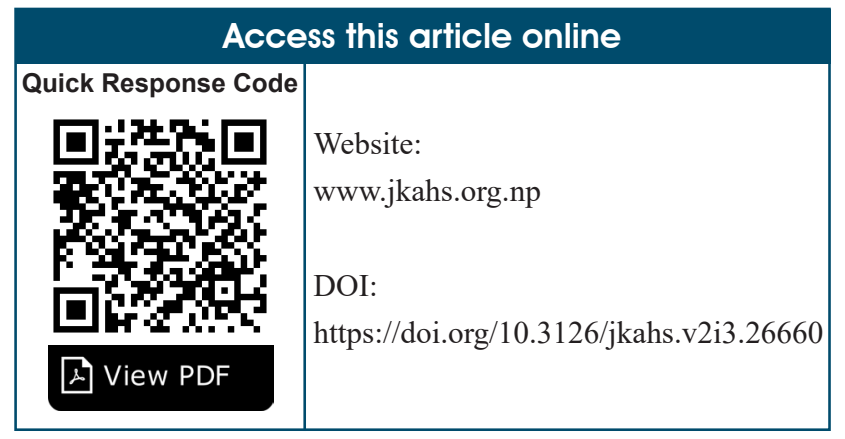

\section{Article Info.}

How to cite this article?

Shakya D, Chaudhary R, Shakya D, Shakya B. Quality of Life and Disability in Stroke Survivors. Journal of Karnali Academy of Health Sciences. 2019;2(3): 227-233.

Received: 11 Oct., Accepted: 18 Nov., Published: 11 Dec. 2019

Conflict of Interest: None, Source of Support: None 


\section{INTRODUCTION}

Medical advances in stroke treatment have prolonged the lives of stroke survivors but has given rise to increase in disability and hence a decreased quality of life (QOL). ${ }^{1}$

Globally, $70 \%$ of strokes and $87 \%$ of both strokerelated deaths and disability-adjusted life years occur in low and middle income countries. ${ }^{2}$ Strokes mainly affect individuals at the peak of their productive life. ${ }^{2}$ Approximately $90 \%$ of stroke survivors have compromised functions and half of them need assistance in activities of daily living (ADL) ${ }^{3-6} \mathrm{~A}$ considerable proportion of costs is caused by longterm care, rehabilitation, nursing, and reduction of work productivity. ${ }^{5,6}$

Many studies worldwide and in Nepal have focused on risk factors and profile of stroke patients..$^{7-9}$ As stroke affects multiple areas of life, basic factors assessing impact of stroke on these areas like QOL, disability, satisfaction and well-being need to be included as outcome measures to determine patient's prognosis. Hence, the researcher attempts to assess the QOL of stroke survivors in Nepal and measure disability in them six months after stroke.

\section{MATERIALS AND METHODS}

Descriptive cross sectional study design was adopted to carry out the study. The data was collected by face to face interview in the Neuromedicine and Neurosurgery outpatient departments (OPD) of Kathmandu Medical College (KMC) for 6 months from January to June 2019. Ethical approval was obtained from the Institutional Review Committee of KMC (Reference number 1009201811) and written informed consent was taken from all the participants.

Patients above the age of 18 and who have had stroke at least six months prior to the time of data collection were included in the study. Quality of life can only be seen when the patients have recovered from their acute disease and hence is usually seen six months post event. ${ }^{10}$ Patients who were already dependent regarding ADL before their stroke event, those mentally not able to give consent and information and those too sick to participate in the study were excluded.

Purposive, non-probability sampling technique was used to take patients attending the Neuromedicine and Neurosurgery OPDs of KMC.

Quality of life was assessed using 'Health related quality of life in stroke patients (HRQOLISP)' questionnaire and disability was measured using the 'World health organization disability assessment schedule (WHODAS 2.0)'. Both the tools have 7 domains each, given by the author themselves. Both are standard tools with measured validity and reliability. ${ }^{11,12}$

Collected data was coded and entered into Statistical Package for Social Science (SPSS) version 16 for statistical analysis. Confidentiality was maintained. Mean, median, standard deviation and Pearson's correlation were used during analysis. Mann Whitney $\mathrm{U}$ test was used to calculate the $\mathrm{p}$ value.

\section{RESULTS}

A total of 155 respondents were included in the final analysis. Patients with higher quality of life were found to have lesser disability (Table 5).

Among the 155 respondents, majority had ischemic stroke $(80 \%)$, more than half had stroke for less than one year $(58 \%)$, more than two third had only one admission (67\%), 11\% still smoked, $8 \%$ drank alcohol and only half of them exercised (50\%). Comorbidities were present in more than three fourth $(76 \%)$ of the respondents.

The descriptive characteristics of the sample are given in Table 1. 
Table 1: Socio-demographic variables $(n=155)$

\begin{tabular}{lc}
\hline \hline \multicolumn{1}{c}{ Variable } & Frequency (\%) \\
\hline Age & $28(18.1)$ \\
$\leq 50$ years & $127(81.9)$ \\
$>50$ years & \\
Mean age: $61.62 \pm 14$ years & \\
Sex & \\
Male & $89(57.4)$ \\
Female & $66(42.6)$ \\
Education & \\
Illiterate & $75(48.4)$ \\
$<10$ years of formal education & $56(36.1)$ \\
$>10$ years of formal education & $24(15.5)$ \\
Occupation & \\
Earning & $67(43.2)$ \\
Not earning & $88(56.8)$ \\
Marital status & \\
Single & $6(3.9)$ \\
Married & $123(79.4)$ \\
Widow/widower & $26(16.8)$ \\
Monthly family income & \\
$<$ NRs 50,000 & $122(78.7)$ \\
NRs 50,000-1,00,000 & $27(17.4)$ \\
$>$ NRs 1,00,000 & $6(3.9)$ \\
\hline
\end{tabular}

The quality of life was found to be better in the 'ecosocial' domain and worst in the 'soul' domain. The domain and final quality of life mean scores are given in Table 2.

Table 2: Health related quality of life domain and final mean score

\begin{tabular}{lcc}
\hline \hline \multicolumn{1}{c}{ Quality of life domains } & Mean score & Rank \\
\hline Ecosocial & $65.5 \pm 14.8$ & 1 \\
Physical & $64.5 \pm 20.5$ & 2 \\
Cognitive & $64.2 \pm 18.5$ & 3 \\
Spiritual interaction & $58.0 \pm 14.5$ & 4 \\
Psycho-emotional & $57.7 \pm 16.6$ & 5 \\
Spirit & $57.4 \pm 16.9$ & 6 \\
Soul & $57.3 \pm 14.0$ & 7 \\
HRQOLISP final mean score & $60.6 \pm 13.6$ & \\
\hline
\end{tabular}

HRQOLISP: Health related quality of life in stroke patients
'Getting along with people' and 'Self care' domains (lesser score meaning lesser disability) and worst in the 'Life activities: school/ work' domain. The domain and final disability mean scores are given in Table 3.

Table 3: Disability domain and final mean scores

\begin{tabular}{lcc}
\hline \multicolumn{1}{c}{ Disability domains } & Mean score & Rank \\
\hline Getting along with people & $39.5 \pm 26.2$ & 1 \\
Self care & $39.5 \pm 29.5$ & 2 \\
Getting around & $41.0 \pm 33.9$ & 3 \\
Understanding and & $44.5 \pm 22.0$ & 4 \\
communicating & $52.7 \pm 21.3$ & 5 \\
Participation in society & $53.2 \pm 35.8$ & 6 \\
Life activities-Household & $55.4 \pm 33.5$ & 7 \\
Life activities-School/ Work & $46.0 \pm 23.6$ & \\
WHODAS final mean score & 46 disability \\
\hline WHODAS: World health & organization & \\
assessment schedule & & \\
\hline
\end{tabular}

Respondents who had hemorrhagic stroke, only one admission and those who did not exercise had a better quality of life. Similarly, patients with less than 10 years of formal education, those who were not earning and those with comorbidities had more disability (Table 4).

There was no significant difference in quality of life or disability in terms of other independent variables under consideration such as sex, marital status, perceived family support, hemisphere, duration of illness, smoking and alcohol intake.

Table 4: Association of independent variables with quality of life and disability

\begin{tabular}{|c|c|c|}
\hline Variables & Quality of life & Disability \\
\hline \multicolumn{3}{|l|}{ Education } \\
\hline $\begin{array}{l}\leq 10 \text { years of formal } \\
\text { education }\end{array}$ & 61.1 & 43.5 \\
\hline \multirow{2}{*}{$\begin{array}{l}>10 \text { years of formal } \\
\text { education }\end{array}$} & 62.6 & 33.0 \\
\hline & p: 0.25 & $\mathrm{p}: 0.025^{*}$ \\
\hline \multicolumn{3}{|l|}{ Occupation } \\
\hline Earning & 62.5 & 38.0 \\
\hline \multirow[t]{2}{*}{ Not earning } & 60.0 & 50.0 \\
\hline & p: 0.25 & p: $0.001^{*}$ \\
\hline
\end{tabular}




\begin{tabular}{lcc}
\hline \multicolumn{1}{c}{ Variables } & Quality of life & Disability \\
\hline Comorbidities & & \\
Present & 59.2 & 46.2 \\
Absent & 62.1 & 34.8 \\
& p: 0.96 & p: $0.018^{*}$ \\
Type & & \\
Ischemic & 60.0 & 44.6 \\
Hemorrhagic & 66.7 & 35.9 \\
& p: $0.038^{*}$ & p: 0.217 \\
Number of & & \\
admissions & & \\
1 time & 62.8 & 42.4 \\
$>1$ times & 58.0 & 46.2 \\
& p: $0.009^{*}$ & p: 0.089 \\
Exercise & & \\
Present & 59.4 & 42.0 \\
Absent & 64.3 & 44.6 \\
& p: $0.002^{*}$ & p: 0.66 \\
\hline
\end{tabular}

*Significant at $0.05 \quad \mathrm{p}$ calculated using Mann level of significance Whitney U test

Correlation analysis of continuous variables showed better quality of life with lesser age, higher monthly family income and higher Barthel index score (lesser disability). In the same way, higher disability was found in respondents with higher age and lower Barthel index score (Table 5).

\section{Table 5: Correlation of continuous} independent variables with quality of life and disability scores

\begin{tabular}{llcc}
\hline \multicolumn{1}{c}{ Variables } & †r value & p value \\
\hline QOL score & Age & -0.302 & $<0.01^{* *}$ \\
& Monthly family & 0.163 & $0.042^{*}$ \\
& income & & \\
& Duration of & 0.066 & 0.416 \\
& illness & & \\
& Barthel index & $0.793^{* *}$ & $<0.01^{* *}$ \\
Disability & Age & 0.46 & $<0.01 * *$ \\
score & Duration of & -0.005 & 0.95 \\
& illness & & \\
& Barthel index & -0.66 & $<0.01 * *$ \\
QOL score & Disability score & -0.799 & $<0.01 * *$ \\
\hline *Significant at 0.05 level of & QOL: Quality of life \\
significance & & & \\
\hline ** Significant at 0.01 level of significance & \\
\hline
\end{tabular}

\section{DISCUSSION}

During analysis of quality of life, the psychoemotional, spirit and soul domains were most affected whereas the physical, intellectual and ecosocial domains were most affected in a study done by Owolabi in Nigeria. ${ }^{13}$ This shows that in Nepalese population, the emotional and spiritual aspects of life get compromised more during stroke. The lack of financial support and health insurance may have caused the frustration and the lack in a person's belief system.

The mean QOL score is $60.6 \pm 13.6$ which is quite less as compared to that is Ghanaian population14 $(69 \pm 13.3)$ or Nigerian population15 (73.5 \pm 9.1$)$ depicting lesser quality of life in Nepalese population.

Similarly, life activities (work), was the domain most affected during calculation of disability. Hence, stroke patients find it most difficult to carry out their work responsibilities due to disability. This is in contrast with the study done by Cerniauskaite et $\mathrm{al}^{5}$ where 'participation in society' is the most affected domain.

Statistically significant difference was found in quality of life in terms of type of stroke, number of admissions and exercise. Quality of life was found to be better in respondents with hemorrhagic stroke. In contrast to this was the result of a study done in Brazil by Carod-Artal et al ${ }^{16}$ and Nigeria by Owolabi ${ }^{15}$ where there was no difference in QOL scores in ischemic and hemorrhagic strokes. This discrepancy in results may be because the number of patients with hemorrhagic stroke taken in this study are less than that of ischemic stroke.

Respondents who were admitted only once had better quality of life. This is quite obvious because those admitted more than once did so because of some health problems and ailments that may have decreased their quality of life.

Respondents who did not exercise had better quality of life. Though paradoxical, this may be because those who had more severe disease and could not walk were undergoing physiotherapy which was also included in exercise. 
QOL was not associated with other independent variables like sex, education, occupation, marital status, perceived family support, comorbidities, hemisphere, duration of illness, smoking and alcohol intake. This is similar to the studies done by Owolabi ${ }^{15}$ and Carod-Arta $1^{16}$ where these variables did not show association with QOL. But this is in contrast to the study done by Akubakar ${ }^{17}$ where sex, education and disability showed significant correlation with QOL.

Regarding disability, respondents who had less than 10 years of formal education, those who were not earning and those who did not have comorbidities had more disability. People with less education may not have been able to explore the treatment options that could lead to more disability. At the same time those respondents who were not earning were so because they had more disability and hence could not work. This is in line with the study done in Italy. ${ }^{5}$ Higher comorbidities in respondents seems to have caused more disability as they were more debilitated by extra diseases beside stroke.

Correlation analysis of quality of life showed statistically significant negative correlation with age and positive correlation with monthly family income and Barthel index. Elderly population hence had worse quality of life. This is in contrast with the study done in Brazil where age and QOL had weak correlation and no significant association. ${ }^{16}$ This discrepancy may be because to larger sample in the Brazilian study. Quality of life increased with increase in monthly family income which shows the importance of financial component for adequate treatment and physical and mental well-being.

Barthel index signifies more disability with lesser score ${ }^{18}$ Hence, quality of life was found to be better with higher score of Barthel index. A study conducted in Brazil is also in agreement with this finding. ${ }^{16}$ This means the QOL is poor with more disability and attention needs to be given to improving the physical concerns of disability during rehabilitation of stroke patients to improve their QOL.

Regarding disability measured by WHODAS 2.0, there was significant positive correlation of disability with age meaning higher the age more the disability. However, a significant negative correlation of disability was found with Barthel index, meaning higher the Barthel index score, less the disability.

A significant negative correlation as found between quality of life measured by HRQOLISP and disability measured by WHODAS 2.0.5,19 This also depicts that lesser the disability, better the quality of life in patients.

However, a smaller sample size and study in a single institute limits the generalizability of the findings. As this is a cross sectional study, it also does not cover the changes in QOL and disability over time. Also, as respondents who were too sick to participate in the study were excluded, the QOL and disability scores may not depict the true burden of the disease.

\section{CONCLUSIONS}

The study concludes that disability greatly affects the QOL and every measure should be taken to lower the disability, making the patients more capable to perform daily activities, earn a living and hence have an improved the quality of life. Attention should be given to domains that are mainly affected in quality of life (soul) and disability (life activities: school/work) during rehabilitation of stroke patients.

\section{Acknowledgements}

Ms. Alisha Thapa for helping in data collection.

\section{REFERENCES}

1. Benjamin EJ, Blaha MJ, Chiuve SE, Cushman M, Das SR, Deo R, et al. Heart Disease and Stroke Statistics-2017 Update: A Report From the American Heart Association. Circulation [Internet]. 2017 [cited 2018 Aug 16];135(10):e146-603. Available from: http://circ.ahajournals.org/doi: $\quad$ 10.1161/ CIR.0000000000000485

2. Johnson W, Onuma O, Owolabi M, Sachdev S. Stroke: A global response is needed. Bulletin of the World Health Organization [Internet]. 2016 Sep 1 [cited 2018 Aug 16];94(9):634A-635A. 
Available from: http://www.who.int/entity/ bulletin/volumes/94/9/16-181636.pdfdoi: 10.1161/CIR.0000000000000485

3. Arene N, Hidler J. Understanding Motor Impairment in the Paretic Lower Limb After a Stroke: A Review of the Literature. Top Stroke Rehabil [Internet]. 2009 Sep 8 [cited 2018 Aug 16];16(5):346-56. Available from: http:// www.ncbi.nlm.nih.gov/pubmed/19903653doi: 10.1310/tsr1605-346

4. Carvalho-Pinto BPB, Faria CDCM. Health, function and disability in stroke patients in the community. Brazilian J Phys Ther [Internet]. 2016 [cited 2018 Aug 13];20(4):355-66. Available from: http://www.ncbi.nlm.nih. gov/pubmed/27556392doi: $\quad$ 10.1590/bjptrbf.2014.0171

5. Cerniauskaite M, Quintas R, Koutsogeorgou E, Meucci P, Sattin D, Leonardi M, et al. Quality-of-Life and Disability in Patients with Stroke. Am J Phys Med Rehabil [Internet]. 2012 Feb [cited 2018 Jul 30];91(13 Suppl 1):S39-47. Available from: http://www.ncbi. nlm.nih.gov/pubmed/22193309doi: 10.1097/ PHM.0b013e31823d4df7

6. Truelsen T, Piechowski-Jóźwiak B, Bonita R, Mathers C, Bogousslavsky J, Boysen G. Stroke incidence and prevalence in Europe: A review of available data [Internet]. Vol. 13, European Journal of Neurology. 2006 [cited 2018 Aug 23]. p. 581-98. Available from: http://www. ncbi.nlm.nih.gov/pubmed/16796582doi: 10.1111/j.1468-1331.2006.01138.x

7. Devkota KC, Thapamagar SB, Malla S. Retrospective analysis of stroke and its risk factors at Nepal Medical College Teaching Hospital. Nepal Med Coll J [Internet]. 2006 [cited 2018 Aug 16];8(4):269-75. Available from: http://www.nmcth.edu/images/gallery/ Editorial/fKCK2Krishna_Chandra_Devkota. pdf

8. Maskey A, Parajuli M, Kohli SC. A Study of Risk Factors of Stroke in Patients Admitted in Manipal Teaching Hospital, Pokhara. population of a country is relevant to understanding. Kathmandu Univ Med J (KUMJ) [Internet]. 2011 [cited 2018 Aug 16];9(36):244-7. Available from: www.cdc.gov/doi: 10.3126/ kumj.v9i4.6337

9. Shaik MM, Loo KW, Gan SH. Burden of stroke in Nepal. Int J Stroke [Internet]. 2012 Aug 13 [cited 2018 Aug 13];7(6):517-20. Available from: http://www.ncbi.nlm.nih. gov/pubmed/22691158doi: $\quad$ 10.1111/j.17474949.2012.00799.x

10. van Mierlo ML, van Heugten CM, Post MWM, Haj $\square \mathrm{s}$ TRS, Kappelle LJ, VisserMeily JMA. Quality of Life during the First Two Years Post Stroke: The Restore4Stroke Cohort Study. Cerebrovasc Dis [Internet]. 2015 Nov 19 [cited 2018 Aug 13];41(12):19-26. Available from: http://www. karger.com/?doi=10.1159/000441197 doi $=10.1159 / 000441197$

11. Ojo Owolabi M. Psychometric properties of the HRQOLISP-40: A novel, shortened multiculturally valid holistic stroke measure. Neurorehabil Neural Repair. 2010 Nov 16;24(9):814-25. doi: $10.1177 / 1545968310369113$

12. Kostanjsek N, Chatterji S, Rehm J. Measuring Health hand Disability Manual for WHO Disability Assessment Schedule WHO DAS 2.0 WHO Library Cataloguing-in-Publication Data Measuring Health and Disability: Manual for WHO Disability Assessment Schedule (WHODAS 2.0) / edited by TB Üstün [Internet]. 2010 [cited 2018 Aug 14]. Available from: http://apps.who.int/iris/bitstream/ handle/10665/ 43974/9789241547598 eng.pdf;jsessionid=914A26E4EF3367 A418343A98A5667968? sequence $=1$

13. Owolabi MO. Determinants of health-related quality of life in Nigerian stroke survivors. Trans R Soc Trop Med Hyg [Internet]. 2008 Dec [cited 2018 Aug 13];102(12):121925. Available from: http://www.ncbi.nlm. nih.gov/pubmed/18556034 doi: 10.1016/j. trstmh.2008.05.003 
14. Donkor ES, Owolabi MO, Bampoh PO, Amoo PK, Aspelund T, Gudnason V. Profile and health-related quality of life of Ghanaian stroke survivors. Clin Interv Aging [Internet]. 2014 [cited 2019 Sep 12];9:1701-8 Available from: http://www.ncbi.nlm.nih.gov/ pubmed/25336935 doi: 10.2147/CIA.S62371

15. Owolabi MO, Ogunniyi A. Profile of healthrelated quality of life in Nigerian stroke survivors. Eur J Neurol. 2009 Jan;16(1):54-62. doi: 10.1111/j.1468-1331.2008.02339.x

16. Carod-Artal FJ, Stieven Trizotto D, Ferreira Coral L, Menezes Moreira C. Determinants of quality of life in Brazilian stroke survivors. J Neurol Sci [Internet]. 2009 Sep 15 [cited 2018 Aug 13];284(1-2):63-8. Available from: http:// www.ncbi.nlm.nih.gov/pubmed/19411080 doi: 10.1016/j.jns.2009.04.008
17. Abubakar SA, Isezuo SA. Health related quality of life of stroke survivors: experience of a stroke unit. Int J Biomed Sci [Internet]. 2012 Sep [cited 2018 Aug 14];8(3):183-7. Available from: http://www.ncbi.nlm.nih.gov/ pubmed/23675271

18. Mahoney FI, Barthel DW. Functional Evaluation: The Barthel Index. Md State Med J. 1965 Feb;14:61-5.

19. Doan Q V., Brashear A, Gillard PJ, Varon SF, Vandenburgh AM, Turkel CC, et al. Relationship between disability and healthrelated quality of life and caregiver burden in patients with upper limb poststroke spasticity. PM R [Internet]. 2012 Jan [cited 2018 Jul 30];4(1):4-10. Available from: http://www. ncbi.nlm.nih.gov/pubmed/22200567 doi: 10.1016/j.pmrj.2011.10.001 